\title{
Analisis Framing Pemberitaan "Kata Pribumi" dalam Pidato Anies Baswedan di Mediaindonesia.co.id dan Republika.co.id
}

\author{
Rizki Matondang, Septianda*) \\ Program Studi Ilmu Komunikasi Universitas Muhammadiyah Sumatera Utara dan \\ Jurnalis Foto Kantor Berita Antara, Indonesia \\ koresponden: Rizkims.matondang@gmail.com
}

\begin{abstract}
ABSTRAK
Berita adalah informasi yang penting dan menarik perhatian banyak orang. Penyajian berita pun harus mempertimbangkan aspek waktu. Setiap berita terikat dengan waktu dan karenanya kecepatan penyajian berita patut menjadi perhatian. Kita mengenal istilah "tiada hari tanpa berita". Salah satu cara yang digunakan untuk mengungkapkan bagaimana cara yang digunakan media massa membangun konstruksi atas sebuah realitas adalah dengan framing. Menganalisis framing tentunya dibutuhkan media pembanding, dalam penelitian ini dua media yang dianalisis adalah media online mediaindonesia.com dan republika.co.id. Pada penelitian ini menggunakan metode analisis framing model Zhongdang Pan dan Gerald M. Kosicki yang merupakan hasil pengembangan dari teori Van Djik sebagai analisis data, yakni: Sintaksis, Skrip, Tematik, dan Retoris. Hasil penelitian menunjukkan wartawan dan mediaindonesia.com dalam pemberitaan mengenai kata pribumi dalam pidato Anies Baswedan lebih menonjolkan kata - kata pasif yang menimbulkan kontra bagi pembaca yang membacanya, sedangkan wartawan dan media republika.co.id dalam pemberitaan mengenai kata pribumi dalam pidato Anies Baswedan lebih menampilkan pemberitaan yang bersifat netral.
\end{abstract}

Kata Kunci : Berita, Analisis Framing, Mediaindonesia.com dan Republika.co.id.

\begin{abstract}
News is important information and attracts many people's attention. Presentation of news must also consider aspects of time. Every news is time bound and hence the speed of news presentation deserves attention. We know the term "no day without news". One way to express how the mass media constructs a reality is through framing. Analyzing framing is certainly needed by comparison media, in this study the two media analyzed are online media mediaindonesia.com and republika.co.id. In this study using the Zhongdang Pan and Gerald M. Kosicki framing model analysis methods which are the results of the development of Van Djik's theory as data analysis, namely: Syntax, Script, Thematic, and Rhetorical. The results showed reporters and mediaindonesia.com in reporting on native words in Anies Baswedan's speech more emphasized passive words which caused contra for readers who read them, whereas Journalists and media republika.co.id in reporting on native words in Anies Baswedan's speech were more showing news that is neutral.
\end{abstract}

Keywords : News, Analysis Framing, mediaindonesia.com dan republika.co.id.

\section{Pendahuluan}

Perjalanan Pemilihan Gubernur DKI Jakarta periode 2017-2022 putaran ke-dua merupakan pemilihan kepala daerah ketiga bagi Kota Jakarta yang dilakukan secara langsung menggunakan sistem pencoblosan. hal ini menjadi fokus tersendiri bagi masyarakat Jakarta maupun diluar Jakarta. Faktor yang mendorong dari fokus masyarakat ini ialah calon pasangan petahana yaitu ( Basuki Tjahya Purnama - Djarot Saiful Hidayat ) dan ( Anies Baswedan Sandiaga Uno ). Di dalam pemilihan Gubernur DKI Jakarta Periode 2017 - 2022 ini sendiri penuh gejolak. Maraknya ujaran kebencian, isu, dan sara (Suku, Agama, Ras, dan Antar golongan).

Anies Baswedan - Sandiaga Uno menjadi gubernur DKI Periode 2017 - 2022, pada 
tanggal 16 november 2017 Anies Baswedan - Sandiaga Uno resmi dilantik oleh Presiden Republik Indonesia Bapak Ir Joko Widodo di Istana Negara. Di dalam pidato pertama Anies Baswedan sebagai Gubernur baru DKI Jakarta menimbulkan kontroversi bagi kalangan masyarakat Jakarta maupun masyarakat Indonesia yang mendengarnya. Terselip kata Pribumi dalam pidato pertama Anies Baswedan sebagai Gubernur baru DKI Jakarta.

Pribumi ialah orang asli, warga Negara asli atau penduduk asli adalah setiap orang yang lahir di suatu tempat, wilayah atau negara dan menetap di sana dengan status orisinal, asli atau tulen sebagai kelompok etnis yang diakui sebagai suku bangsa bukan pendatang dari negeri lainnya. Pribumi bersifat autochton (melekat pada suatu tempat). Secara lebih khusus, istilah pribumi ditujukan kepada setiap orang yang terlahir dengan orang tua yang juga terlahir di suatu tempat tersebut.

Pemberitaan mengenai kata pribumi inipun beragam, sebagai contoh media online mediaindonesia.com yang pemiliknya adalah Surya Paloh dan juga media republika.co.id yang pemiliknya adalah Agoosh Yoosran. Mengingat pemberitaan kata pribumi yang dimuat wartawan berita media online ini membangun paradigma sosial tersendiri bagi netizen yang membacanya.

Berita adalah informasi yang penting dan menarik perhatian banyak orang. Penyajian berita pun harus mempertimbangkan aspek waktu. Setiap berita terikat dengan waktu dan karenanya kecepatan penyajian berita patut menjadi perhatian. Kita mengenal istilah "tiada hari tanpa berita". Disisi lain, media masssa dan wartawan pun berkepentingan untuk mengelola pemberitaan secara optimal, tidak hanya sebatas menyajikan berita. Atas dasar itu, penyajian berita jurrnalistik harus memperhatikan sifat-sifat berita, seperti aktual, objektif, akurat, menarik perhatian dan bertanggung jawab (Yunus, 2010:45-46).

Salah satu cara yang digunakan untuk mengungkapkan bagaimana cara yang digunakan media massa membangun konstruksi atas sebuah realitas adalah dengan framing. Menurut Sobur, "analisis framing untuk mengetahui bagaimana media membingkai atau mengemas isu atau peristiwa melalui teks yang terdapat dalam isi media". Framing pertama kali dilontarkan oleh Beterson tahun 1955 (Sobur, 2012:161).

Dedy N. Hidayat (dalam Bungin, 2015:207) menjelaskan bahwa analisis framing dapat digunakan untuk melihat bagaimana upaya media menyajikan sebuah event yang mengesankan objektifitas, keseimbangan dan non partisipan dan mengemasnya sedemikian rupa sehingga khalayak mudah tergiring ke dalam kerangka (framing) pendefinisian realitas tertentu yang dilakukan oleh media melalui pemilihan kata, bahasa, penggunaan simbol dan sistem logika tertentu.

Dalam menganalisis framing tentunya dibutuhkan media pembanding. Dalam penelitian ini dua media yang dianalisis adalah media online mediaindonesia.com dan republika.co.id jika dilihat dari teks berita yang diterbitkan di laman website masing masing kedua media, adanya kecenderungan di salah satu media yang membingkai berita tersebut.

\section{Kerangka Teori}

Salah satu cara yang digunakan untuk mengungkapkan bagaimana cara yang digunakan media massa membangun konstruksi atas sebuah realitas adalah dengan framing. Menurut Sobur, "analisis framing untuk mengetahui bagaimana media membingkai atau mengemas isu atau peristiwa melalui teks yang terdapat dalam isi media". Framing pertama kali dilontarkan oleh Beterson tahun 1955. (Sobur, 2012:161).

Dedy N. Hidayat (Bungin, 2008:207) menjelaskan bahwa analisis framing dapat digunakan untuk melihat bagaimana upaya media menyajikan sebuah event yang mengesankan objektifitas, keseimbangan dan non partisipan dan mengemasnya sedemikian rupa sehingga khalayak mudah tergiring ke dalam kerangka (framing) pendefinisian realitas tertentu yang dilakukan oleh media melalui pemilihan kata, bahasa, penggunaan simbol dan sistem logika tertentu.

Analisis framing merupakan pendekatan konstruktivis yang dipakai untuk menjelaskan 
tentang news discourse dengan fokus pada konseptulisasi teks-teks berita secara sintaksis, skrip, tematik, struktur retorika, sehingga akan diperoleh bukti atau temuan terhadap framing dari pemberitaan media massa terhadap isu dalam teks-teks berita. Zondang Pan dan Kosicki (Bungin, 2008:206).

\section{Metode}

Metode analisis yang digunakan dalam penelitian ini adalah analisis framing dengan pendekatan model Zhongdang Pan dan Gerald M. Kosicki. Menurut Pan dan Kosicki, framing didefinisikan sebagai proses membuat suatu pesan menjadi lebih menonjol, menempatkan informasi lebih daripada yang lain sehingga khalayak lebih tertuju pada pesan tersebut (Eriyanto, 2002:252).

Penelitian ini merupakan penelitian Analisis Framing maka, narasumber dalam penelitian ini berita yang diterbitkan oleh mediaindonesia.com dan republika.co.id mengenai pemberitaan pribumi dalam pidato anies baswedan. Pada mediaindonesia.com sebanyak 1 berita dan pada republika.co.id juga sebanyak 1 berita.

Teknik pengumpulan data dalam penelitian ini hanya dokumentasi. Metode dokumentasi adalah cara pengumpulan informasi dan data - data melalui pengujian arsip dan dokumen dokumen. Metode dokumentasi adalah metode mencari data mengenai variable yang berupa, catatan, transkip, buku, surat kabar, majalah, prasasti, notulen rapat, agenda, dan sebagainya.

Teknik analisis data yaitu menganalisis data yang berhasil dikumpulkan oleh si peneliti melalui perangkat metodologi tertentu (Krisyantono, 2008:58). Pada penelitian ini menggunakan metode analisis framing model Zhongdang Pan dan Gerald M. Kosicki yang merupakan hasil pengembangan dari teori Van Djik sebagai analisis data, yakni: Sintaksis, Skrip, Tematik, dan Retoris.

\section{Hasil dan Pembahasan}

Pada Mediaindonesia.com, struktur sintaksis dijelaskan bahwa "kata pribumi" dalam pidato Anies Baswedan sebagai Gubernur DKI Jakarta melanggar Inpres Nomor 26 Tahun 1998. Headline yang digunakan mediaindonesia.com menggunakan kata - kata pernyataan seperti: "Gunakan dan Langgar" hal ini membuat headline tersebut menjadi kontra.

Mediaindonesia.com juga menggunakan kata - kata pasif yang ada pada lead berita tersebut, narasumber Peneliti Retorika Dan Media Dari Universitas Atma Jaya Yogyakarta, Desideria Murti, mengatakan Anies Baswedan dinilai lalai dalam melakukan proses rekonsiliasi dengan menyebut kata pribumi. Dan diyakini bakal berdampak negatif bagi perjalanan demokrasi di Indonesia. Hal yang dapat diambil dari isi teks berita tersebut bahwasannya kata "dinilai lalai, diyakini, dan bakal" merupakan banyak menggunakan kata - kata yang bersifat pasif atau tidak tegas.

Pada struktur skrip ini sudah dipaparkan unsur $5 \mathrm{~W}+1 \mathrm{H}$, yaitu unsur what (peristiwa apa yang terjadi: Anies melanggar aturan Inpres Nomor 26 tahun 1998), where (dimana peristiwa itu terjadi: Balai Kota DKI Jakarta, Jalan Medan Merdeka Selatan No. 8-9 Blok B RT.11/RW.2, Gambir, Kota Jakarta Pusat, Daerah Khusus Ibukita Jakarta 10110), when (kapan peristiwa itu terjadi: Selasa, 17 Oktober 2017), who ( siapa yang terlibat dalam peristiwa ini: Anies Baswedan, Desideria Murti, Puti Sinansari), why (kenapa peristiwa ini terjadi: karena pidato pertama Anies Baswedan sebagai Gubernur DKI Jakarta), how (bagaimana peristiwa itu terjadi: Anies melakukan pidato pertama nya sebagai Gubernur DKI Jakarta periode 2017 - 2022. Dalam hal ini Peneliti Bidang Sosial Dari Wirata Institute, Puti Sinansari, dan juga Peneliti Retorika Dan Media Dari Universitas Atma Jaya Yogyakarta, Desideria Murti, menyikapi bahwasannya Anies Baswedan dinilai lalai dalam melakukan proses rekonsiliasi sehingga menyebutkan kata pribumi)

Secara tematik artikel ini berisikan pendapat - pendapat dari Peneliti Retorika Dan Media, dan juga dari Peneliti Bidang Sosial Dari Wiratama Institute, dari pendapat kedua peneliti tersebut menyatakan bahwasannya Anies seharusnya lebih fokus dan mengedepankan program kerja, data - data mengenai hal yang belum dikerjakan oleh pendahulunya. Dan visi misinya. Tujuannya agar 
masyarakat kembali fokus pada rasionalitas kerja seorang Gubernur.

Pada struktur retoris ini menggambarkan bahwa kata pribumi dalam pidato Anies Baswedan sangatlah lawas ketika didengar oleh masyarakat Indonesia, hal ini juga disukung oleh bagaimana wartawan mediaindonesia.com membuat headline dengan menggunakan kata "Gunakan dan Langgar" hal ini juga sebagai pernyataan bahwasannya Anies Baswedan melanggar aturan Inpres 26/1998 yang sudah ditetapkan.

Pada berita replubika.co.id untuk struktur sinaksis, dijelaskan bahwa Wakil Presiden Jusuf Kalla mengatakan pidato pertama Anies Baswedan usai dilantik sebagai Gubernur DKI Jakarta adalah dalam konteks sejarah, bukan diskrimintaif. Dalam pernyataan ini Jusuf Kalla berbicara sebagai Pemimpin Negara, dan juga pernyataan yang disampaikan Jusuf Kalla juga bersifat netral. Cara wartawan mengisahkan fakta melalui pemimpin negara merupakan suatu hal pembeda bagi media republika.co.id dalam memberitakan kata pribumi dalam pidato anies baswedan sebagai gubernur dki jakarta.

Pada struktur ini sudah dipaparkan unsur $5 \mathrm{~W}+1 \mathrm{H}$. Yaitu unsur what (peristiwa apa yang terjadi: jusuf kalla mengatakan pidato Anies mengenai kata pribumi sesuai konteksnya), where ( dimana peristiwa itu dilaksanakan: kantor Wapres, Jakarta), when ( kapan peristiwa itu terjadi: Selasa 17, Oktober 2017), who (siapa yang terlibat dalam peristiwa ini: Jusuf Kalla, Anies Baswedan), why (kenapa peristiwa ini terjadi: karena pidato pertama Anies Baswedan sebagai Gubernur DKI Jakarta), how (bagaimana peristiwa itu terjadi: Anies melakukan pidato pertama nya sebagai Gubernur DKI Jakarta periode 2017 - 2022.

Secara tematik, pemberitaan ini berisikan tentang isi pidato Anies Baswedan yang menggunakan kata pribumi sesuai konteksnya, pidatonya bicara tentang kolonial, konteksnya dia menyampaikan tentang sejarah, jadi jangan hanya potong satu kata. Wakil Presiden menyatakan hal tersebut menanggapi pidato Anies seusai dilantik sebagai Gubernur DKI Jakarta di Istana Kepresidenan.

Pada struktur retoris ini, wartawan dan media republika.co.id mengambil pernyataan dari pemimpin Negara yaitu Jusuf Kalla, beliau menyampaikan kata - kata aktif dalam wawancara nya kepada wartawan. Anies Baswedan yang menggunakan kata pribumi pada pidato pertamanya sebagai Gubernur DKI jakarta sesuai konteksnya. Disini digambarkan bahwa Jusuf Kalla menjelaskan bahwasannya pidato Anies menjelaskan tentang kolonial dan menceritakan tentang sejarah, dan tidak adanya kesalahan yang disampaikan oleh Anies Baswedan dalam pidato pertamanya sebagai Gubernur DKI Jakarta. Dalam hal inilah wartawan dan media republika.co.id lebih menonjolkan pemberitaan yang netral kepada pemberitaan kata pribumi pada pidato pertama Anies Baswedan sebagai Gubernur DKI Jakarta.

\section{Kesimpulan}

Wartawan dan mediaindonesia.com dalam pemberitaan mengenai kata pribumi dalam pidato Anies Baswedan lebih menonjolkan kata - kata pasif yang menimbulkan kontra bagi pembaca yang membaca nya. Kata "dinilai, diyakini, bakal" merupakan kata - kata pasif sehingga terjadinya pernyataan yang tidak tegas di teks berita mediaindonesia.com.

Strategi mediaindonesia.com menulis fakta dan menekankan fakta pada pemberitaan mengambil dari narasumber peneliti retorika dan peneliti bidang sosial. Dan juga menonjolkan kata perintah di headline mediaindonesia.com dengan menggunakan kata "Gunakan dan Langgar"

Wartawan dan media republika.co.id dalam pemberitaan mengenai kata pribumi dalam pidato Anies Baswedan lebih menampilkan pemberitaan yang bersifat netral, hal ini tidak lepas dari pernyataan narasumber Wakil Presiden Jusuf Kalla.

Penggunaan kata aktif pada republika.co.id juga menjadi pemisah atau pembeda dari pemberitaan yang disampaikan mediaindonesia.com. jusuf kalla sendiri mengatakan pidato pertama anies baswedan usai dilantik sebagai gubernur dki jakartabadalah dalam konteks sejarah, bukan deskriminatif. Hal ini yang dapat meredamkan asumsi masyarakat tentang pemberitaan negatif mengenai kata pribumi pada pidato pertama Anies Baswedan sebagai Gubernur DKI Jakarta. 
Vol 2 No. 2, 2019, 65-69

DOI: https://doi.org/ 10.30596/persepsi.v2i2.3945

Bagi media diharapkan agar lebih objektif dalam penyampaian, dan juga tidak menyinggung atau merugikan sebelah pihak. Karena terkadang terdapat kata - kata tersebut didalam judul, ataupun kata - kata yang terdapat dalam teks media itu sendiri. Seharusnya media memberitakan berita yang objektif dan juga tidak menyinggung atau merugikan sebelah pihak agar menciptakan pembaca yang lebih rasionalitas dalam mengartikan sebuah pemberitaan yang disampaikan. Diharapkan dalam membaca berita agar tidak langsung terpengaruh oleh berita yang dimuat surat kabar. Tetapi lebih bijak menyikapi pemberitaan tersebut agar tidak salah arti dalam mengartikan berita tersebut.

\section{Daftar Pustaka}

Bungin, Burhan. (2015). Konstruksi Sosial Media Massa. Jakarta: Prenadamedia Group. Eriyanto. (2012). Analisis Framing: Konstruksi, Ideology, dan Politik Media. Yogyakarta: LkiS. Krisyantono, Rachmat. (2008). Teknis Pratis Riset Komunikasi. Jakarta: Kencana. Sobur, Alex. (2012). Analisis Teks Media. Bandung: Remaja Rosdakarya. Yunus, Syafirudin.(2010). Jurnalistik Terapan. Jakarta: Ghalia Indonesia.

Affandi, Hakimul i. (2004). Akar Konflik Sepanjangn Zaman, Elaborasi Pemikiran Ibn Khaldun. Yogyakarta: Pustaka Pelajar.

Baron, Byrne. (2005). Psikologis Sosial Jilid 2. Jakarta: Erlangga.

Chusnuddin, Ahmad Arif. (2016). Kota Sepak Bola Itu Bernama Surabaya: dalam Sirajudin Hasbi dan Ferry Triadi Sasono [ed] (2016), Sepakbola 2.0. Yogyakarta: Fandom

Miles, B. Mathew dan Michael Huberman. (1992). Analisis Data Kualitatif Buku Sumber Tentang Metode-metode Baru. Jakarta: UIP.

Rusdiana, A. (2015). Manajemen Konflik. Bandung: Cv Pustaka Setia.

Susan, Novri. (2009). Pengantar Sosiologi Konflik. Edisi Revisi. Jakarta: Prenada Media Group. Susetyo, Budi. D. P. (2010). Stereotip dan Relasi Antar Kelompok. Yogyakarta: Graha Ilmu. 